\title{
OS POVOS INDÍGENAS E O DISCURSO DESENVOLVIMENTISTA RETRATADOS NO ENSINO DE HISTÓRIA DO BRASIL EM MEIO A DITADURA MILITAR (1964-1984)
}

\author{
Cristiano Antônio Pochmann ${ }^{1}$ \\ Carlos Renato Carola ${ }^{2}$
}

\begin{abstract}
Resumo
Este artigo buscou identificar, através da análise de livros didáticos de História do Brasil, editados entre os anos de 1964 a 1984, a forma como os povos indígenas foram afetados pelo discurso desenvolvimentista implantado pelos governos militares no Brasil. O estudo consiste em uma abordagem qualitativa e documental. Nesta pesquisa foi possível constatar que dentre as obras analisadas, nenhuma apresentou qualquer discussão referente aos povos indígenas, focando-se exclusivamente nos supostos benefícios que este processo de desenvolvimento poderia trazer à população brasileira. Os resultados desse discurso desenvolvimentista implantado no Brasil entre os anos de 1964 a 1984 em relação aos povos indígenas, só puderam ser realmente observados ao se buscar a leitura de duas obras não didáticas, uma editada no ano de 1978, Vítimas do Milagre: O desenvolvimento e os Índios do Brasil de Shelton H. Davis e do $1^{\circ}$ Relatório do comitê estadual da Verdade: O genocídio do povo Waimiri-Atroari, apresentado no ano de 2012.
\end{abstract}

Palavras-chave: Povos Indígenas, Livros Didáticos, Ditadura Militar, Discurso Desenvolvimentista.

\section{INDIGENOUS PEOPLES AND THE DEVELOPING SPEECH PICTURED IN THE TEACHING OF BRAZIL HISTORY DURING THE MILITARY DICTATORSHIP (1964-1984)}

\begin{abstract}
This article sought to identify, through the analysis of Brazilian History textbooks, edited between the years 1964-1984, the way indigenous peoples were affected by the developing speech deployed by the military governments in Brazil. The study has a qualitative and documental approach. This research reveals that, among the analyzed textbooks, none of them had any discussion related to indigenous peoples; they focused exclusively on the supposed benefits that this developing process could bring to Brazilians. The results of this developing speech implemented in Brazil between the years 1964-1984 in relation to indigenous peoples could only be perceived at the reading of two non-didactic works, one edited in 1978: Miracle Victims: Development and Brazil's Indians written by Shelton H. Davis, and the 1st Report of the state committee of Truth: the genocide of the Waimiri- Atroari people, presented in 2012.
\end{abstract}

Keywords: Indigenous Peoples, textbooks, Military Dictatorship, Developing Speech.

\section{Introdução}

No momento em que lembramos os cinquenta anos do golpe militar de 1964 no Brasil, golpe esse que implantou uma das ditaduras mais perversas da história, a sociedade brasileira foi convidada a refletir sobre os crimes cometidos pelos agentes do governo militar a partir das investigações realizadas pela Comissão da Verdade. Essa comissão foi criada por Lei no ano de 2011, tendo por objetivo apurar crimes contra a violação dos Direitos Humanos entre o ano de 1964 e 1988, crimes que até hoje não foram julgados.

A motivação principal para a Criação da Comissão se deve ao fato de que, no Brasil, os crimes de tortura e assassinato cometidos pelos agentes de Estado durante o regime militar ficaram

\footnotetext{
${ }^{1}$ Mestre em Educação - UNESC. Instituto Federal Catarinese - Câmpus Santa Rosa do Sul. E-mail: cristiano@ifcsombrio.edu.br

${ }^{2}$ Doutor em História - USP. Universidade do Extremo Sul Catarinense - Unesc. E-mail: crc@unesc.net
} 
impunes. Na visão de juristas, historiadores e, principalmente, na visão das pessoas que sofreram algum tipo de dano físico ou psicológico pelo regime autoritário, a Lei de Anistia (Lei 6.68329/08/1979) beneficiou os torturadores. O texto da Lei, que foi aprovada pelo Congresso Nacional em agosto de 1979, concede anistia a todos os condenados por crimes de natureza política, exceto os "condenados pela prática de crimes de terrorismo, assalto, sequestro e atentado pessoal". Constata-se, portanto, uma omissão ou um silêncio no texto da Lei de Anistia em relação aos crimes de tortura e assassinato praticados por agentes do Estado. Entretanto, ao mesmo tempo em que o texto da Lei contempla a visão e os interesses políticos do governo militar, ele também não elimina a possibilidade de interpretação de que os crimes de tortura e assassinatos de natureza política podem e devem ser julgados.

Todo governo, inclusive o ditatorial, necessita de legitimidade institucional e apoio popular. Nesse sentido, uma das estratégias do governo militar brasileiro foi a propaganda da política desenvolvimentista. O governo dos generais tinha consciência de que com o controle da inflação e crescimento econômico, conquistava-se a simpatia da população em geral e minava-se o discurso de "crise" social e econômica dos opositores do regime; sabia-se que a ideologia desenvolvimentista era uma ideologia que agradava quase todos os setores da sociedade. Por isso, era preciso difundir as imagens do desenvolvimento de um modo que a população percebesse o surgimento de um “novo" Brasil, ideia que foi simbolizada e propagada no slogan "Pra Frente Brasil". Assim, um dos modos de propagação do desenvolvimentismo foi a exaltação das grandes obras de infraestrutura, tais como: construção das grandes rodovias, usinas hidrelétricas, portos e grandes empresas estatais (Embratel, Telebras, etc). De um modo geral, a propagação da política desenvolvimentista foi difundida em todos os espaços institucionais e informais da sociedade brasileira. Entretanto, há pelos menos três setores da sociedade em que a propaganda do desenvolvimento foi estrategicamente eficiente e impactante: no espaço empresarial, nos meios de comunicação (rádio, TV e imprensa escrita) e no sistema escolar.

Esta pesquisa explicita discursos e imagens do desenvolvimentismo difundidos no sistema escolar brasileiro durante a ditadura militar de 1964. Nosso objetivo principal foi observar e identificar as representações da política desenvolvimentista realizadas pelos governos ditatoriais; perceber como os livros didáticos de ensino de História e Moral e Cívica, editados entre os anos de 1964 a 1984 explicam a construção das grandes obras de infraestrutura e a situação dos povos indígenas, uma vez que muitas destas obras foram construídas em seus territórios. 
Além da historiografia que aborda o tema da ideologia desenvolvimentista, observamos 12 livros didáticos editados pelas principais editoras brasileiras da época: Companhia Editora Nacional, FTD, Edições Loyola, Saraiva, Ática e Moderna.

Neste trabalho usamos o termo desenvolvimentismo como uma ideologia; e o sentido de ideologia na perspectiva sociológica, ou seja: "um sistema de ideias (crenças, tradições, princípios e mitos) interdependentes, sustentado por determinado grupo social de qualquer natureza ou dimensão" (Costa, 2012, p. 2). Assim, abordamos, neste estudo, as representações da ideologia desenvolvimentista no ensino de História do Brasil, articulado com a questão indígena e ambiental.

Trata-se de uma pesquisa orientada pela abordagem de História Ambiental no campo da História da Educação brasileira. A História Ambiental teve seu início na década de 1970, embora já houvesse anos antes, discussões em torno desse movimento que buscava, não só refletir sobre a relação do homem com a natureza, mas também discutir o tema socioeconômico no que tange à forma como o homem explorou, e ainda explora, sem a menor preocupação com o futuro, florestas, mares e, consequentemente, os povos que ainda resistem e habitam esses ecossistemas.

\section{Ideologia desenvolvimentista}

Faz-se necessário compreender primeiramente o momento politico e social que o Brasil se encontrava entre nos anos de 1964 a 1984. Em março de 1964, militares, políticos e parte da sociedade civil colocaram em prática o golpe militar que depôs um governante eleito democraticamente e instauraram no país uma ditadura que durou cerca de vinte anos.

Tal como nas demais ditaduras da América Latina, a ditadura brasileira não hesitou em fazer uso e abuso do poder ditatorial: o congresso nacional foi fechado; diversos deputados foram cassados; a imprensa foi censurada; centenas de cidadãos (políticos, artistas, intelectuais) foram obrigados a se exilarem no exterior; e a prática da tortura, o assassinato e as perseguições políticas se tornaram práticas rotineiras nos porões obscuros de regime militar, esse período foi ainda caracterizado por eleições presidenciais sem a participação da população brasileira.

Ao mesmo tempo em que se fazia uso abusivo da tortura, o regime ditatorial implantado no Brasil investia no marketing que procurava demonstrar que o país estava pavimentando o seu futuro pelos trilhos da "Ordem e do Progresso". As músicas criadas no clamor ufanista do regime de 1964 - "Pra Frente Brasil", "Eu te amo meu Brasil” e "Este é um país que vai pra frente" - evidenciam de forma cristalina a aposta do regime no ideal desenvolvimentista.

Mas afinal, que é desenvolvimentismo? No Brasil, o termo "desenvolvimentista" ganhou múltiplos sentidos. Para o Centro Internacional Celso Furtado de Políticas para o 
Desenvolvimento, (2015) o "desenvolvimentismo foi uma resposta aos desafios e oportunidades criados pela Grande Depressão dos anos 30”. No passado brasileiro, o desenvolvimentismo foi uma estratégia de desenvolvimento realizada com o objetivo de superar o Estado oligárquico do período anterior a 1930. O Estado desenvolvimentista nacionalista foi adotado por outros países da América Latina, assim como por países asiáticos, entre os quais a Coreia do Sul, Taiwan e Singapura. Tratase de uma ideologia que se baseia numa teoria estruturalista de desenvolvimento em combinação com uma visão macroeconômica keynesiana.

$\mathrm{Na}$ América Latina, o desenvolvimentismo se configurou na forma de uma ideologia nacionalista que conferia ao Estado um papel protagonista. Os marcos iniciais desta ideologia surgiram na primeira metade do século $\mathrm{XX}$, no contexto inicial de industrialização dos países latino-americanos. Independentemente da posição política de seus atores, o pensamento desenvolvimentista parte de uma visão interna do atraso econômico e cultural do seu respectivo país (subdesenvolvimento) e projeta um futuro promissor apostando no crescimento econômico, potencializado por meio da industrialização.

No Brasil, a trajetória do desenvolvimentismo vem suscitando estudos, pesquisas e debates desde a década de 1980, neste percurso, os positivistas contribuíram com a gênese do desenvolvimentismo brasileiro formulando ideias e ações que pudessem impulsionar o Brasil no suposto caminho natural para a evolução e o progresso. Assim, preconizavam um papel iluminista às ações governamentais, pois entendiam "ser dever do Estado ajudar a sociedade a rumar para o progresso.” (Fonseca, 2004, p. 245). Tal como o liberalismo e o marxismo, o pensamento positivista é uma das ideologias que exerceram forte influência nas concepções desenvolvimentistas da sociedade brasileira.

No âmbito da ciência econômica ou do pensamento econômico, também se observa diferentes vertentes desenvolvimentistas. Conforme Valente (2009), no contexto do regime militar de 1964 havia pelos menos três tendências desenvolvimentistas no Brasil. As concepções desenvolvimentistas formuladas pelo Instituto Superior de Estudos Brasileiros (ISEB), pela Escola Superior de Guerra (ESG) e pela Escola Paulista de Sociologia ligado à USP. As discussões promovidas pelo ISEB, criado no ano de 1955, estavam fortemente relacionadas as políticas desenvolvimentistas do governo de Juscelino Kubitschek.

A Escola Superior de Guerra iniciou suas atividades no ano de 1949, ligada a consultorias e programas governamentais relacionados aos governos francês e norte-americano, com o intuito de "preparar pessoal de alto nível no sentido de exercer funções de direção e planejamento da segurança nacional". Muitas das medidas adotadas pela Escola Superior de Guerra estavam ligadas 
ao pensamento do Instituto Superior de Estudos Brasileiros, diferenciando-se principalmente aos temas ligados ao modelo de governo implantado, um modelo ditatorial. Assim, a doutrina básica da Escola Superior de Guerra fundamentava-se no ideário de controlar o meio político e social, onde somente as elites seriam capazes de compreender e implementar os chamados "objetivos nacionais permanentes" (VALENTE, 2009).

Ao contrário do que a Escola Superior de Guerra e o Instituto Superior de Estudos Brasileiros propuseram, a teoria fundada por pensadores ligados à Escola de Sociologia da Universidade de São Paulo apresentava um modelo de desenvolvimento ligado ao capital externo, onde empresas e capitais externos teriam livre caminho para se implantarem no País (Valente, 2009, p. 188).

Os objetivos traçados e esperados por cada uma das tendências desenvolvimentistas são diferentes, mas todas compartilham a mesma visão conceitual sobre a ideia de natureza: a natureza como um conjunto de recursos naturais que devem atender as necessidades e interesses humanos, seja para fins sociais ou para fins lucrativos.

\section{O sistema escolar, os livros didáticos e os povos indígenas}

Uma das características do Estado Moderno contemporâneo é a existência de um sistema escolar nacional. De um modo geral, esta peculiaridade começou a ser efetivada a partir do século XVIII, quando todas as nações ocidentais que almejaram conquistar status de civilização moderna começaram a investir na implantação de um sistema nacional de educação, realidade amplamente concretizada na segunda metade do século XX. No modelo civilizatório da sociedade moderna, portanto, a educação escolar ocupa um lugar de centralidade e prioridade. Para viabilizar a funcionalidade do sistema, o Estado investe na construção de uma arquitetura padronizada de espaços físicos, desenvolve uma política legislativa e curricular. Investe na formação de professores e gestores, cria políticas para o acesso e distribuições de recursos didáticos para uso em sala de aula.

A medida que se implanta um sistema escolar também se desenvolve dialeticamente uma cultura escolar, uma cultura constituída por atores (professores, gestores, alunos) que sofrem influência de teorias, ideologias e forças políticas da sociedade ao mesmo tempo em que exercem uma autonomia que lhes possibilita formar novas identidades.

Ainda hoje, um dos recursos pedagógicos imprescindíveis do ensino escolar é o livro didático. O uso do livro didático em sala de aula, não importando a disciplina a ser estudada, esteve por muito tempo relacionado ao exercício de memorização e reprodução dos conteúdos. De acordo com Rocha (2008, p. 132), os livros eram elaborados com a intenção de levar o aluno a memorizar e 
repetir lições, pouco ajudando na sua formação intelectual, ou seja, aprender era sinônimo de reproduzir.

A história produzida e retratada nos livros didáticos sempre esteve relacionada ao momento histórico político nacional, ou seja, foi utilizada para transparecer ou esconder o que os governos desejavam. O livro didático era utilizado como forma de enaltecer símbolos nacionais e certos acontecimentos em detrimento a outros. Conforme Reis (2012), no caso dos livros didáticos de História, particularmente, torna-se interessante examinar os temas e as situações que podem estar excluídos ou silenciados.

Outro fator de suma importância com relação ao livro didático é a sua condição de documento histórico, até mesmo devido à sua importância perante o processo educativo. "Esse tipo de material faz parte do universo da cultura escolar, residindo aí a importância da sua utilização para a compreensão das práticas escolares no interior das instituições educativas ao longo da história da educação" (CORRÊA, 2000, p. 11).

Como objeto pedagógico, professores e alunos se apropriam do livro didático com objetivo de ensinar e aprender. Como fonte de pesquisa no campo da História e, particularmente, na História da Educação, ele se constituiu numa fonte documental valiosa.

A relação entre livro escolar e escolarização permite pensar na possibilidade de uma aproximação maior do ponto de vista histórico acerca da circulação de ideias sobre o que a escola deveria transmitir/ensinar e, ao mesmo tempo, saber qual concepção educativa permearia a proposta de formação dos sujeitos escolares. Nesse sentido, então, esse tipo de fonte pode servir como um indicador de projeto de formação social desencadeado pela escola. [...], aliás, dependendo do período histórico no qual for tomado como fonte, esse tipo de material pode ser considerado como o portador supremo do currículo escolar no que tange aos conhecimentos que eram transmitidos nas diferentes áreas, quando se constituiu em única referência tanto para professores quanto para alunos (CORRÊA, 2000, p. 13).

O livro didático, fonte de informação e de conhecimento para alunos de todo o País, independentemente da classe social e faixa etária, também sofre influências do mercado editorial e principalmente das medidas e preceitos governamentais. "Tais livros sofrem, como nenhum outro, as influências das políticas educacionais da época de sua produção. Como produto mercadológico, o livro didático sofre também a influência do mercado editorial[...]” (SALLES, 2011, p. 9). Levandose em consideração que o mercado editorial procura atender aos interesses e reivindicações de sua clientela predominante, que no caso dos livros didáticos são os governos e a comunidade escolar (pais, alunos e professores), podemos inferir que os livros escolares se constituem em valiosas fontes de pesquisa onde estão arquivados a memória coletiva de uma determinada época histórica. 
Por meio dos livros didáticos podemos perceber a difusão da ideologia desenvolvimentista no meio escolar. Em 1969, o governo militar brasileiro decretou (Decreto-Lei 869) a substituição das disciplinas de História, Geográfica, Filosofia e Sociologia pelas de Educação Moral e Cívica e Organização Social e Política Brasileira. Mesmo assim, a necessidade do ensino de história e geografia não foi eliminada do currículo escolar, e nem as obras didáticas e historiográficas saíram do mercado editorial. No regime político de 1964, patriotismo e desenvolvimentismo eram ideologias estratégicas para conferir legitimidade e apoio popular; e muitos destes ideais chegaram e foram transmitidos pelas escolas por meio dos livros didáticos.

O livro didático, sobretudo o de História, ainda está permeado por uma concepção positivista da historiografia brasileira, que primou pelo relato dos grandes fatos e feitos dos chamados "heróis nacionais", geralmente brancos, escamoteando, assim, a participação de outros segmentos sociais no processo histórico do País. Na maioria deles, despreza-se a participação das minorias étnicas, especialmente índio/as e negros/as. Quando aparecem no livro didático, seja por meio de textos ou de ilustrações, índios/as e negros/as são tratados/as de forma pejorativa, preconceituosa ou estereotipada (SILVA, 2014, p. 3).

No contexto do regime militar de 1964, o sistema escolar brasileiro foi oficialmente preparado para exercer o seu papel "patriótico" ensinando aos jovens e crianças conhecimentos e valores que legitimavam e consolidavam o modelo de Estado imposto pelo regime: um Estado capitalista com ordem e progresso. A politica legislativa para a educação escolar e o conteúdo dos livros didáticos evidenciam de forma cristalina este novo papel atribuído à escola e aos professores.

Observando-se os livros didáticos como lugares de memória, identificamos as principais tendências teóricas e ideológicas de uma época. Neste trabalho em particular, procuramos identificar nos livros escolares as configurações da ideologia desenvolvimentista e o lugar dos povos indígenas do Brasil, difundidos no período do regime militar de 1964-1984. Consideramos relevante abordar a questão indígena por três razões principais: a) No passado como no presente, a sociedade brasileira vem historicamente promovendo, ou no mínimo sendo "cúmplice", com a prática de genocídio das culturas indígenas; ${ }^{3}$ b) Diversas obras desenvolvimentistas foram construídas nos territórios indígenas, ao custo de uma violência brutal com repercussão internacional e censura nacional; c) Os povos indígenas foram pioneiros na defesa do meio ambiente e na resistência à violência ambiental.

\footnotetext{
${ }^{3}$ As diversas formas de violência e extermínio contra os povos indígenas durante a ditadura de 1964, podem ser constatadas no Relatório da Comissão Nacional da Verdade (2014, p. 203-262), onde se verifica a "banalidade do mal" contra os povos indígenas Xetá, Tapayuna (Beiço-de-Pau), Avá-Canoeiro do Araguaia, Waimiri-Atroari, SateréMawé, Cinta Larga, Krenak e Aikewara.
} 
No ensino de História, nem sempre se reservou um espaço adequado para a história dos povos indígenas e afro-brasileiros. Por isso, houve a necessidade de uma imposição legal. Com a promulgação da Lei n. 11.645, de 10 março de 2008, lei que altera o artigo 26 da LDB de 1996, a escola fica obrigada a oferecer o estudo de história dos povos afro descentes e indígenas.

Art. $1^{\circ} \mathrm{O}$ art. 26-A da Lei $\mathrm{n}^{\mathrm{0}}$ 9.394, de 20 de dezembro de 1996, passa a vigorar com a seguinte redação:

Art. 26-A. Nos estabelecimentos de ensino fundamental e de ensino médio, públicos e privados, torna-se obrigatório o estudo da história e cultura afrobrasileira e indígena.

$\S 1^{\circ}$ O conteúdo programático a que se refere este artigo incluirá diversos aspectos da história e da cultura que caracterizam a formação da população brasileira, a partir desses dois grupos étnicos, tais como o estudo da história da África e dos africanos, a luta dos negros e dos povos indígenas no Brasil, a cultura negra e indígena brasileira e o negro e o índio na formação da sociedade nacional, resgatando as suas contribuições nas áreas social, econômica e política, pertinentes à história do Brasil.

$\S 2^{\circ}$ Os conteúdos referentes à história e cultura afro-brasileira e dos povos indígenas brasileiros serão ministrados no âmbito de todo o currículo escolar, em especial nas áreas de educação artística e de literatura e história brasileiras (BRASIL, 2008).

Outro ponto importante na mudança da forma como os povos indígenas são representados nos livros didáticos, é o Programa Nacional de Livros Didáticos que trouxe avanços também na qualidade das obras destinadas à distribuição, proporcionando uma melhora significativa não só em termos de qualidade do material, mas, principalmente, nas discussões que são apresentadas nos livros didáticos, além de proporcionar o avanço no ensino de todas as disciplinas.

\section{Os povos indígenas na rota da expansão desenvolvimentista}

Ao estudar a formação do modelo de desenvolvimento do País implantado entre os anos de 1964-1984 no Brasil, tendo como fontes de pesquisa os livros didáticos de ensino de História e Educação Moral e Cívica, constatou-se uma indiferença generalizada em relação aos direitos de vida dos povos indígenas. De um modo geral, pode-se afirmar que nas décadas de 1960, 1970 e 1980, a discussão referente a esse assunto ainda estava restrita a setores minoritários da população. Havia críticas e denúncias por parte de lideranças comunitárias e de intelectuais engajados com a causa indígena, mas não havia consciência ambiental e humanitária da sociedade brasileira com a preservação tanto da natureza quanto dos povos indígenas.

No Brasil, alguns pensadores e indigenistas já traziam à tona, discussões referentes aos direitos dos povos indígenas na década de 1950 ao mesmo tempo que questionam e denunciam o ímpeto ambiental destrutivo da política desenvolvimentista. Darcy Ribeiro, por exemplo, produziu 
diversas obras, tais como Culturas e línguas indígenas do Brasil, editada no ano de 1957, A política indigenista brasileira, no ano de 1962, Os índios e a civilização, em 1970, entre tantos outros livros e ensaios, onde se toma conhecimento do rastro de violência e destruição da expansão desenvolvimentista.

Outras importantes discussões e estudos foram realizados pelos irmãos Villas-Bôas, que junto a Darcy Ribeiro e outros indigenistas, foram os responsáveis pela criação do Parque Nacional do Xingu. A criação desse parque foi de extrema importância, tendo em vista a preservação da vida, da cultura e dos costumes de vários povos indígenas.

Nos estudos sobre os povos indígenas, o papel do Serviço de Proteção aos Índios (SPI, 19101967) também é severamente contestado em função da conivência ou mesmo ação direta de violência contra os povos indígenas; e a Fundação Nacional do Índio, órgão criado pelo governo militar de 1964 em substituição ao Serviço de Proteção aos Índios I, também não se imbuiu de uma vontade política contra a violência aos povos indígenas. Pelas fontes documentais e historiográficas, percebe-se que na prática o "Serviço de Proteção aos Índios" foi muito mais um instrumento de Estado para preparar e legitimar a expansão desenvolvimentista nos territórios indígenas.

No Brasil, a crítica ambiental e a denúncia da violência contra os povos indígenas, portanto, tem uma longa história. O problema é que esta crítica não tem tido força suficiente para competir com a ideologia desenvolvimentista. A situação dos povos indígenas ganha um pouco mais de atenção quando a crítica vem dos países considerados mais “desenvolvidos”, principalmente quando vinda dos Estados Unidos ou dos países da Europa Ocidental. Neste sentido, pode-se dizer que a obra Vítimas do Milagre, o desenvolvimento e os índios do Brasil, do antropólogo estadunidense Shelton H. Davis (1978), contribuiu para fortalecer a crítica socioambiental já existente no território brasileiro; e por ser estrangeiro e ainda norte-americano, Davis não estava na mesma condição de risco tal como os intelectuais brasileiros que ousavam questionar a ordem e o progresso da ditadura nacional, como no caso de Darcy Ribeiro que foi forçado a se exilar no Uruguai. Por isso, o antropólogo norte-americano se sentiu mais à vontade para problematizar e desmistificar os feitos perversos da obra desenvolvimentista, como se pode observar no título de alguns capítulos de seu livro: A política indigenista e a situação dos índios brasileiros (1957-1968); a história econômica da Amazônia e os planos de desenvolvimento no período pós-guerra; a desintegração das tribos Cintas Largas e Suruí; a política indigenista e a frente de expansão de mineração na Amazônia; os efeitos sociais e ecológicos do Programa Polamazônia com a ascensão da agroindústria.

Para tentar abrandar o processo que envolveu a Funai e seus servidores com relação ao ato de “civilizar" os povos indígenas, ou seja, destruindo a cultura e o seu modo de vida, o governo federal 
criou a Guarda Rural Indígena, com o objetivo de substituir o homem branco no controle social dos povos indígenas. Após algum tempo, a Fundação Nacional do Índio passou a receber denúncias contra a Guarda Rural Indígena, relacionadas a crimes contra os índios, como estupro e espancamento (TV FOLHA, 2012).

Além da criação da Guarda Rural Indígena, há denúncias relacionadas à criação, no estado de Minas Gerais, de prisões para onde eram encaminhados os índios que não se enquadravam nas normas da Fundação Nacional do Índio. Muitos, ao chegarem às prisões, eram torturados, confinados em solitárias e muitas vezes passavam fome.

Ainda com referência a Guarda Rural Indígena, encontramos um vídeo que apresenta a formatura dos índios da Guarda Rural Indígena, onde é apresentado o desfile da tropa de índios, neste desfile é observamos um homem preso no pau de arara, método de tortura usado pelo governo militar para obter testemunhos dos presos políticos (AGÊNCIA PÚBLICA, 2013).

Enquanto as obras de Darcy Ribeiro e Shelton Davis apresentavam a trágica realidade dos povos indígenas frente a expansão desenvolvimentista, o que se ensinava na escola? Nos livros didáticos de ensino de História do Brasil geralmente se destinava um capítulo superficial e genérico sobre os índios na época do descobrimento do Brasil. Nos capítulos que abordam a história do desenvolvimento econômico, lugar em que se destacam as obras desenvolvimentistas, predomina um silêncio sepulcral sobre a situação dos povos indígenas e sobre os impactos ambientais provocados pela construção das grandes obras.

Ao mesmo tempo em que se faz apologia ao progresso desenvolvimentista, omite-se qualquer consideração sobre a situação dos povos indígenas, reforçando-se o tradicional imaginário, de que os índios, são povos sem cultura e avessos ao trabalho e ao progresso civilizatório. Conforme Grupioni (1995, p. 483), grande parte da sociedade ainda tem este pensamento em virtude do modelo conceitual de história que aprenderam nos livros didáticos que traziam em seus interiores, textos muitas vezes sem a real discussão em torno da vida dos povos indígenas.

Vejamos então o que os livros didáticos ensinavam sobre as obras do desenvolvimentismo e a situação dos povos indígenas. Um exemplo são os relatos apresentados no livro Estudo Dirigido de Educação Moral e Cívica, de Elian Alabi Lucci (1978). O livro exibe o mapa do Brasil com as divisões dos programas que deveriam ter sido executados nas regiões Centro-Oeste, Norte e Nordeste, destacando que essas são as áreas do Brasil que menos receberam investimentos referentes ao processo de desenvolvimento industrial. O livro de Lucci (1978) apresenta o Polamazônia como um importante programa de desenvolvimento para o país. O texto e as imagens configuram a tradicional ideia de vazio demográfico e as potencialidades econômicas que a 
exploração da Amazônia representa para o Brasil. Ressalta-se que o governo estava criando uma infraestrutura para viabilizar o desenvolvimento econômico por meio da exploração agrícola, pecuária e mineral, sem cogitar uma mínima reflexão sobre os impactos socioambientais dos empreendimentos desenvolvimentistas.

Elevar o número de cabeças de gado que compõe o rebanho da Amazônia, bem como programar o desenvolvimento de lavouras selecionadas, principalmente as de caráter permanente, e ainda criar uma infraestrutura necessária ao desenvolvimento da região através de polos de desenvolvimento econômico, agropecuário e agro minerais (LUCCI, 1978, p. 231).

A informação textual é complementada com um mapa do Brasil indicando os polos de desenvolvimento regionais: Polo Nordeste, Polo Centro, Polamazônico, Polos Agropecuários e Polos Agro minerais. Observa-se no mapa a inexistência de polos nas regiões sul e sudeste, indicado a prioridade da política desenvolvimentista do governo militar, uma vez que estas duas regiões já se encontravam em adiantado estado de industrialização em comparação com as demais regiões.

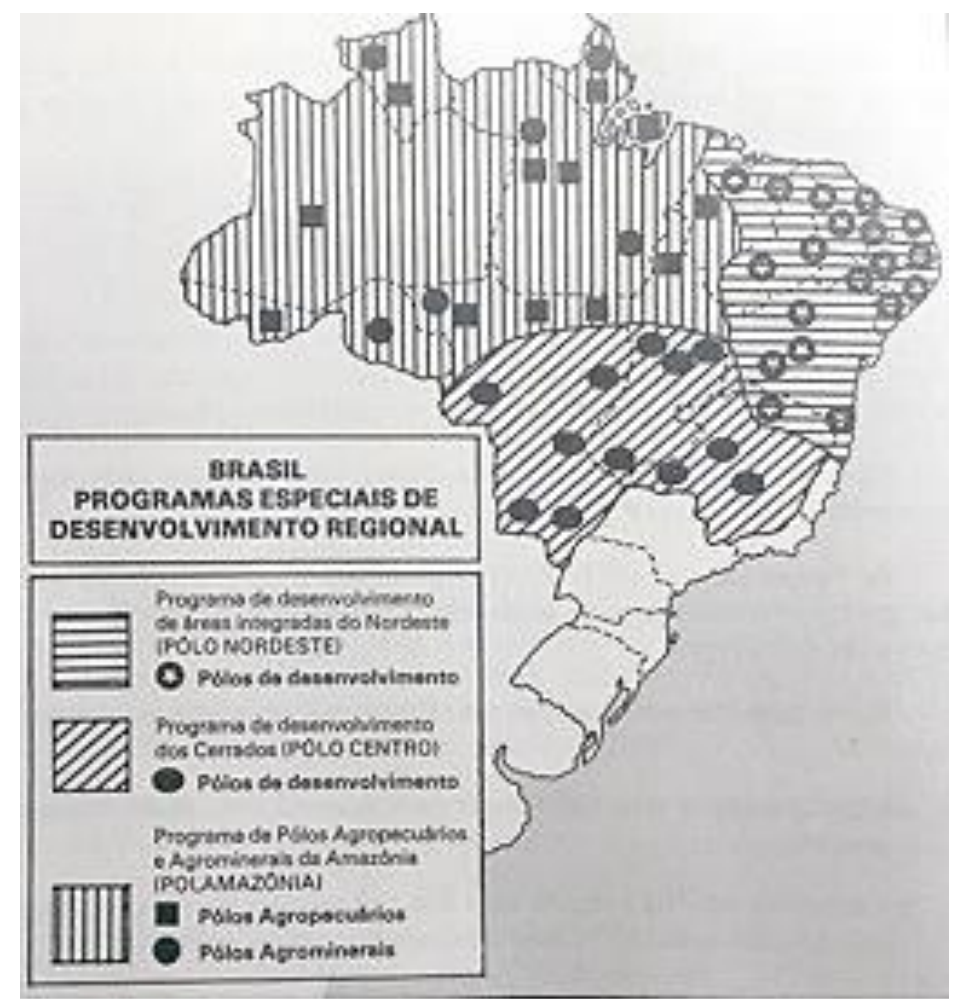

FIGURA 01 - Programas de Desenvolvimento.

Fonte: Lucci, 1978.

Ao analisar os objetivos dos programas governamentais para essas regiões, percebe-se a intenção do governo de estimular a agricultura e a mineração com o intuito de proporcionar um salto no crescimento econômico. Pode-se incluir nos projetos desenvolvimentistas a Transamazônica e outras grandes rodovias que foram construídas com a justificativa de integrar a 
parte menos habitada do Brasil com o restante do país. Ao contrário do que a grande maioria dos livros didáticos ensinavam, a política desenvolvimentista do governo militar privilegiou o interesse econômico de alguns setores empresariais, muitas vezes com o objetivo de beneficiar empresas interessadas em explorar os minérios que se encontravam nessas regiões, abrir espaço para a criação de gado e prospectar madeira, sem a menor preocupação com a degradação ambiental e étnica.

Apesar de já haver uma política indigenista desde a constituição de 1934, o governo militar de 1964 deu continuidade ao processo de expansão das obras desenvolvimentistas considerando os povos indígenas como obstáculos que deveriam ser removidos a qualquer custo. Os povos indígenas eram vistos como empecilhos para o desenvolvimento do país e suas terras eram consideradas vazios demográficos, áreas potencialmente ricas em recursos naturais que deveriam ser exploradas em prol do desenvolvimento nacional. Partes da violência brutal dos grandes empreendimentos estão sendo revelados atualmente através dos relatórios da Comissão da Verdade, violência esta que não tem sensibilizada a grande mídia nacional.

Uma semana depois do massacre do Abomari o sertanista Sebastião Amâncio da Costa, nomeado substituto de Gilberto Pinto na chefia da Frente de Atração Waimiri-Atroari (FAWA), em entrevista ao jornal O Globo, de 06 de janeiro de 1975, assumiu de público as determinações do OF. n $042-\mathrm{E} 2-\mathrm{CONF}$, declarando que faria "uma demonstração de força dos civilizados que incluiria a utilização de dinamite, granadas, bombas de gás lacrimogêneo e rajadas de metralhadoras e o confinamento dos chefes índios em outras regiões do País (COMITÊ DA VERDADE DO AMAZONAS, 2012, p. 49).

Muitas das medidas tomadas pela FUNAI tinham como objetivo proteger o capital privado, tanto nacional quanto estrangeiro, que investiam naquele momento, grandes somas de capitais na região amazônica. A construção de estradas com a justificativa de integrar o País era na realidade uma estratégia para facilitar o escoamento de minerais extraídos da Amazônia, da exploração da madeira e criação de gado nas áreas desmatadas. O governo militar implementou um programa de infraestrutura de modo a viabilizar o desenvolvimento da indústria agropecuária, agro mineral e agroflorestal, sem tomar nenhuma medida de preservação socioambiental, ou seja, não houve nenhuma preocupação em termos de preservação das culturas indígenas e do meio ambiente. O que importava naquele momento era o progresso econômico a qualquer custo.

Por isso, a papel desempenhado pela FUNAI não era efetivamente o de proteção e preservação dos direitos dos povos indígenas, era muito mais o de criar as condições necessárias para a expansão desenvolvimentista nos territórios indígenas. Quando se instituiu a FUNAI em substituição ao antigo SPI em 1967, o seu primeiro estatuto preconizava uma política indigenista de respeito e proteção aos direitos dos povos indígenas, pelo menos formalmente. Entretanto, em 1970 o novo presidente da FUNAI, o General Oscar Jerônimo Bandeira de Mello, anunciou uma 
mudança substancial na política indigenista brasileira. Como assinala Shelton Davis (1978, p. 88), os objetivos da FUNAI foram redefinidos em função da política desenvolvimentista do governo miliar, configurando-se em duas diretrizes gerais: "1) integrar os índios, o mais rápido possível, à economia de mercado em expansão e à estrutura de classes do Brasil; 2) garantir que os índios não oferecer obstáculos à ocupação e colonização da Amazônia.”.

Mas afinal o que se ensinava na escola em relação ao desenvolvimento do Brasil? No âmbito das fontes pesquisadas há, pelo menos, duas formas de representações da mesma realidade. Enquanto na maioria dos livros didáticos de ensino de História e Educação Moral e Cívica faziam apologia ao desenvolvimentismo, nas obras dos antropólogos havia a denúncia referente aos impactos socioambientais. Em Vítimas do Milagre (DAVIS, 1978), por exemplo, o leitor se depara com uma visão de realidade chocante; uma visão onde se destaca a irracionalidade do modelo desenvolvimentista, a devastação das florestas e o genocídio dos povos indígenas, ou seja, um tipo de "banalidade do mal ambiental" pensado e planejado pelas autoridades do governo brasileiro. Segundo Davis (1978, p.15), "as doenças, a morte e o sofrimento humano, que se desencadearam sobre os índios nos últimos anos, são o resultado direto da política de desenvolvimento econômico dos Governos Militares". Em termos comparativos, podemos afirmar que enquanto o governo nazista da Alemanha planejou e executou uma política de "Solução Final" para os judeus (ARENDT, 2013), o governo militar de 1964 também planejou uma "Solução Final" para os povos indígenas.

O Brasil fornece um dos mais claros exemplos modernos de um País onde os direitos das comunidades indígenas foram sacrificados em nome dos interesses maiores do desenvolvimento nacional. Gigantescos projetos rodoviários, de mineração e de pecuária foram planejados para atravessar territórios dos índios na Amazônia Brasileira, e em seu rastro trouxeram doenças, morte e destruição cultural para as tribos indígenas (DAVIS, 1978, p. 12).

A partir de 1971 a FUNAI tornou-se uma agência estratégica para a política desenvolvimentista tanto quanto para a política de genocídio e etnocídio. No episódio das manifestações contrárias à construção da BR-080, rodovia que abriria um trecho de 40 quilômetros pelo Parque Nacional do Xingu, o General Oscar Jerônimo Bandeira de Mello, presidente da FUNAI, expressou de forma cristalina e contundente a lógica colonialista da ideologia desenvolvimentista: “O índio não é cobaia, nem propriedade de meia dúzia de oportunistas. Não se pode deter o desenvolvimento do Brasil por causa do Parque do Xingu" (Jornal Folha da Tarde, 10/03/1971, apud DAVIS, p. 87).

No âmbito do ensino escolar brasileiro, o lugar dos povos indígenas é, na verdade, um nãolugar. Nos livros didáticos editados no período de 1964 a 1984, os índios são representados como 
povos de um passado distante; são representados com os tradicionais termos genéricos, termos que invisibilizam toda a sua complexa diversidade cultural. No contexto do regime militar de 1964, o ensino de História do Brasil é predominante tradicional e positivista, principalmente quando se trata de abordar a realidade dos povos indígenas. Nos livros didáticos tradicionais os índios aparecem nas imagens que ilustram a chegada dos europeus, nas imagens que ilustram a estrutura econômica da colonização portuguesa, ou seja, aparecem como figuras decorativas de uma concepção de história que enaltece a figura do homem branco conquistador e civilizador. São raras as obras didáticas que se propõe a superar o colonialismo cultural que se expressa no modo de ver e representar os povos indígenas. Para Vânia Maria Moreira (2001, p. 87), “[...] a pouca atenção dada à questão indígena pela historiografia brasileira é um claro indício da existência de sérios vícios teóricos e metodológicos presentes na maneira corrente de escrever-se a história de ocupação e colonização territorial.".

A título de exemplo, vejamos o livro de História do Brasil publicado pela Editora Maltese em 1976. Pelo sumário já podemos perceber a concepção geral da obra e o lugar (isto é, o não-lugar) dos povos indígenas na História do Brasil: 1) Os antecedentes do descobrimento; 2) Cabral descobre o Brasil; 3) As invasões; 4) Movimentos Revolucionários (A inconfidência Mineira e a Revolução Republicana de 1817]; 5) Dom João VI no Brasil; 6) A República é Proclamada; 7) $O$ Brasil dos nossos dias. Todos os capítulos são complementados com imagens ilustrativas. A referência aos povos indígenas aparece no segundo e terceiro capítulo - Cabral Descobre o Brasil/As invasões. No capítulo do "descobrimento", destaca-se as tradicionais representações que caracterizam o encontro dos portugueses com os índios; as ilustrações os caracterizam numa posição de submissão aos conquistares europeus. No conteúdo textual descrevem-se os detalhes do "descobrimento", das expedições exploradoras, das primeiras ações colonizadoras e os primeiros resultados das atividades econômicas. Os índios estão presentes em todas as páginas do capítulo, mas somente nas ilustrações. No capítulo seguinte, destina-se um tópico para explicar a formação da "raça brasileira" com a mestiçagem entre o português, o índio e o negro. Apresentam-se informações gerais que explicam a origens dos povos indígenas do Brasil. Fala-se das características dos principais grupos - os tupis, os tapuias, os nu-aruaques e os caraíbas; descreve-se os hábitos e costumes, as crenças e religiões. A descrição textual, no enanto, expressa a tradicional visão do olhar do homem civilizado europeu: "o grau de civilização dos índios era o neolítico, ou da pedra polida" (DINIZ; MALTESE, 1976, p. 44).

No que tange as realizações dos quatro primeiros governos da "Revolução", o livro de História do Brasil da editora Maltese enaltece as realizações desenvolvimentistas de cada 
presidente. Destaca-se, em relação ao governo do Marechal Castelo Branco (1964-1967), a firmeza política não somente por ter libertado o Brasil da subversão comunista e da corrupção que dominava o espaço público, como também da estabilidade da moeda. Do governo do Marechal Costa e Silva (1967-1969) afirma-se que ele "foi um digno continuador do trabalho do seu antecessor: a mesma competência e honestidade no trato da coisa pública”. Sobre o General Emílio Garrastazu Médici, destaca-se que seu governo "teve por objetivos, proporcionar estímulos à iniciativa privada, desenvolver um programa de integração de todos os setores da vida nacional, complementar os projetos relativos aos serviços de comunicação e transportes, a abertura da Transamazônica, a luta contra o analfabetismo, a ocupação demográfica e econômica da Amazônia" (DINIZ; MALTESE, 1976, p. 98). A ilustração usada para complementar a descrição textual é a de uma imagem que mostra o trabalho de homens e máquinas derrubando a floresta no processo de inicial de construção da grande rodovia.

\section{Considerações Finais}

Em síntese, podemos afirmar que o sistema escolar brasileiro se apropria dialeticamente das múltiplas ideologias que estão presentes no ambiente cultural da sociedade brasileira. Tal como em outras instituições, a dinâmica do meio escolar está repleta de tensões e conflitos, de contradições e dissonâncias, assim como de ações de integração, solidariedade e cooperação. Em relação ao ideal desenvolvimentista, no entanto, há muito mais convergência do que tensões conflitivas; muito mais crença do que crítica. Compreende-se que diante da necessidade de legitimidade e apoio popular do governo militar de 1964, a propaganda dos programas desenvolvimentistas se configurava como uma estratégia eficiente. Neste aspecto, os livros didáticos se constituíram em veículos de propaganda do desenvolvimentismo, pois constata-se uma visão ufanista em relação às grandes obras e aos programas de integração regional, tais como: rodovias, usinas, programas de povoamento e colonização, complexos industriais, entre outros. Mesmo nos livros didáticos em que se constata uma visão crítica em relação à política desenvolvimentista, visão esta que emerge a partir da promulgação de Lei de Anistia em 1979, percebe-se que se trata de uma crítica à forma como se implantou as obras do desenvolvimento e não a lógica socioambientalmente insustentável da ideologia desenvolvimentista.

Por meio dos recursos didáticos produzidos para e pelo sistema escolar brasileiro, constatamos a força de coesão e sedução da ideologia desenvolvimentista. No período de 1964 a 1984, percebe-se claramente que o governo ditatorial redefiniu as diretrizes curriculares do ensino escolar e universitário com os objetivos de subordinar o sistema educacional aos imperativos 
desenvolvimentista. Substituíram-se as disciplinas de História e Geografia pelas de Moral e Cívica, e Organização Social e Política Brasileira, mas não se extinguiram os conteúdos de história e geografia.

Como lugares de memória, podemos afirmar que nos livros didáticos de História do Brasil e de Educação Moral e Cívica estão cristalizadas as concepções desenvolvimentistas da sociedade brasileira daquela época; imagens que fazem uma apologia cega e ufanista de um modelo de desenvolvimento que impôs uma política de genocídio aos povos indígenas e uma devastação ambiental imensurável.

No decorrer do século XX, as denúncias contra a devastação ambiental e a violência contra os povos indígenas sempre estiveram na ordem do dia. Marechal Rondon, Irmãos Villas-Bôas, Darcy e Berta Ribeiro, Shelton Davis e centenas de outros intelectuais e ativistas da causa ambiental e indígena, não pouparam esforços no sentido de sensibilizar a sociedade brasileira em direção a um outro modelo de desenvolvimento. Os governos do regime militar de 1964 não somente ignoraram o clamor de justiça e respeito aos povos indígenas e ao meio ambiente natural, como trataram de potencializar e acelerar o máximo possível o ritmo do crescimento econômico, difundindo a irracional ilusão de progresso e prosperidade. Por fim, em termos de violência social e ambiental podemos qualificar o regime militar como um regime de barbárie. Mas uma observação final se faz necessária: em tempos de regime democrático como se encontra a situação atual dos povos indígenas do Brasil?

\section{Referências}

\section{Fonte de Pesquisa}

BONI; BELLUCI. História do Brasil: Império e República. São Paulo: FTD, [198-].

COMISSÃO DIDÁTICA LAUDES. Estudo Sociais: História do Brasil depois da Independência. Rio de Janeiro: Editora Laudes, 1973.

DANTAS, J. História do Brasil: $1^{\circ}$ Grau. São Paulo: Moderna, 1984.

DINIZ, S.; MALTESE, G. Trópico Histórico: História do Brasil. São Paulo: Maltese, 1976.

GALACHE, G.; ZANUY, F.; PIMENTEL, M.T. Construindo o Brasil. 14. ed. São Paulo: Loyola, 1975.

HERMIDA, A. J. B. Compêndio de História do Brasil. 57. ed. São Paulo: Companhia Nacional, 1971.

LUCCI, E.A. TDMC, Trabalho Dirigido de Moral e Civismo $2^{\circ}$ grau. São Paulo: Saraiva, 1978.

SANTOS, J. R. dos. História do Brasil: $2^{\circ}$ grau. São Paulo: Marco Editorial, 1979.

SANTOS, M.J.V. História do Brasil: $6^{\circ}$ série. 14. ed. São Paulo: Ática, 1982. 
SILVA, F. DE A; BASTOS, P. I. A. História do Brasil: colônia, Império e República. 2. ed. São Paulo: Moderna, 1983.

SOUTO MAIOR, A. História do Brasil. 7. ed. São Paulo: Companhia Nacional, 1969.

SOUZA, O. R. História do Brasil: 6º série. 3. ed. São Paulo: Ática, 1984.

VALUCE, L. História do Brasil: ensino de primeiro grau. 62. ed. São Paulo: Brasil, 1975.

\section{Referências}

AGÊNCIA PÚBLICA. Ditadura criou cadeias para índios com trabalhos forçados e torturas. 2013. Disponível em: http://www.historiailustrada.com.br/2014/04/a-ditadura-militar-manteveindios.html\#.U8uu5Fb_w6I> Acesso em: 31 de março de 2014.

ARENDT, H. Eichmann em Jerusalém: um relato sobre a banalidade do mal. Traducción de José Rubens Siqueira. 16. reimpresión. São Paulo: Companhia das Letras, 2013.

BRASIL. Comissão Nacional da Verdade. Relatório: Textos temáticos, v. 2. Brasília: CNV, 2014. 416 p. In: http://www.documentosrevelados.com.br/wpcontent/uploads/2015/02/volume_2_digital.pdf. Acesso em 04/07/2016.

Decreto-Lei n. 869 de 12/09/1969. Dispõe sobre a inclusão da Educação Moral e Cívica como disciplina obrigatória, nas escolas de todos os graus e modalidades, dos sistemas de ensino no País, e dá outras providências. Brasília, DF: 1969.

Lei n. 6.683, de 28/08/1979. Concede anistia e dá outras providências. Brasília, DF: Congresso Nacional, 1979.

. Lei n. 11.645, de 10/03/2008. Altera a Lei n= 9.394, de 20 de dezembro de 1996, modificada pela Lei n. 10.639, de 9 de janeiro de 2003. Estabelece as diretrizes e bases da educação nacional, para incluir no currículo oficial da rede de ensino a obrigatoriedade da temática "História e Cultura Afro-Brasileira e Indígena". Brasília, DF, 1979.

. Lei n. 12.528, de 18/11/2011. Cria a Comissão Nacional da Verdade no âmbito da Casa Civil da Presidência da República. Brasília, DF, 2011.

Centro Internacional Celso Furtado de Políticas para o Desenvolvimento. In: http://www.centrocelsofurtado.org.br/interna.php?ID_S=72. Acesso em 11/05/2015.

COMITÊ DA VERDADE DO AMAZONAS. $1^{\circ}$ Relatório do comitê estadual da Verdade: $\mathrm{O}$ genocídio do povo Waimiri-Atroari. Manaus, 2012. Disponível em:

http://www.dhnet.org.br/verdade/resistencia/a_pdf/r_cv_am_waimiri_atroari.pdf > Acesso em: 15 de abril de 2015.

CORRÊA, R. L. T; O Livro Escolar como Fonte de Pesquisa em História da Educação. Caderno Cedes, v. 20, n. 52, p. 11-24, nov. 2000.

COSTA, F. N. Desenvolvimento do Desenvolvimentismo: do socialismo utópico ao socialismo desenvolvimentismo. Campinas, 2012. Disponível em:

https://www.google.com.br/url?sa=t\&rct=j\&q=\&esrc=s\&source=web\&cd=2\&ved=0CCUQFjAB\& 
url=http\%3A\%2F\%2Fwww.eco.unicamp.br\%2Fdocprod\%2Fdownarq.php\%3Fid\%3D3185\%26tp\% 3Da\&ei=bL9ZVaj5NsK_ggTqtIDIDw\&usg=AFQjCNGcex3GKQBg8TqwVVx1K7yW10_sAw\&si g2=PbIDwNtNOM3IG5wMDlsiYw\&bvm=bv.93564037,d.eXY>. Acesso em 18 de abril de 2015.

DAVIS, S. H. Vítimas do Milagre. O desenvolvimento e os índios no Brasil. Tradução Alexandre Faure Pontual. Rio de Janeiro: Zahar, 1978.

DOSSE, F. A História em Migalhas: dos Annales à Nova História. 2. ed. Tradução Dulce A. Silva Ramos. Campinas, SP: Ed. UNICAMP, 1994.

DUPAS, G. O mito do progresso; ou progresso como ideologia. São Paulo: UNESP, 2006.

FAUSTO, B. História do Brasil. 9. ed. São Paulo: Ed. USP: Fundação para o Desenvolvimento da Educação, 2001.

FONSECA. S.G. A história na educação básica: conteúdos, abordagens e metodologias. In: Seminário Nacional: Currículo em Movimento - Perspectivas Atuais, 1, Belo Horizonte, 2010. p. 1-13. 2010.

FONSECA, P.C.D. Gênese e percursores do desenvolvimentismo no Brasil. Revista Pesquisa e Debate, v. 15, n.2 (26), p. 225-256, 2004.

FRANCO, J. L. de A. e DRUMMOND, José Augusto. Proteção à natureza e identidade nacional no Brasil, nos anos 1920-1940. Rio de Janeiro: Fiocruz, 2009.

FURTADO, C. O mito do desenvolvimento econômico. São Paulo: Paz e Terra, 1974.

GRUPIONI, L.D.B. Livros didáticos e fontes de informações sobre as sociedades indígenas no Brasil. In: A temática indígena na escola: novos subsídios para professores de $1^{\circ} \mathrm{e} 2^{\circ}$ graus /org. Aracy Lopes da Silva e Luís Donizete Benzi Grupioni - Brasília, MEC/MA- RI/UNESCO, 1995.

MARTINEZ, P. Política Indígena. Revista de História, Rio de Janeiro, 14 de abr. 2011. Disponível em: http://www.revistadehistoria.com.br/secao/artigos-revista/politica-indigena>. Acesso em: 09 de fevereiro de 15.

MEIRELlES FILHO, J. O livro de ouro da Amazônia. 5. ed. Rio de Janeiro: EdOURO, 2006.

MOREIRA, V. M. L. Índios no Brasil: marginalização social e exclusão historiográfica. Diálogos Latino Americanos, n. 003, p. 87-113, 2001.

PÁDUA, J. A. Um sopro de destruição: pensamento político e crítica ambiental no Brasil Escravista (1786-1888). 2. ed. Rio de Janeiro: Jorge Zahar, 2004.

PEREIRA, L. C. B. Estado desenvolvimentista, nacionalismo e liberalismo. Trabalho apresentado à reunião anual da Sociedade Brasileira de Ciência Política, Gramado, agosto de 2012. Disponível em: http://www.bresserpereira.org.br/papers/2012/372-Estado-DesenvovimentistaNacionalismo-Liberalismo-exLilian.pdf. Acesso em 11/05/2015.

REIS, T. F.; PRADO, E. M. A ditadura militar brasileira em determinados manuais didáticos da educação básica. Revista Intersaberes, v. 7, n.14, p.278-290, ago./set. 2012.

RIBEIRO, D. Os índios e a civilização: a integração das populações indígenas no Brasil Moderno. 2. ed. Petrópolis-RJ: Vozes, 1977. 
Culturas e línguas indígenas do Brasil. Centro Brasileiro de Pesquisas

Educacionais. 1957.

A politica indigenista brasileira. Ministério da Agricultura. Serviço de Informação Agrícola. 1962.

ROCHA, A. C. D. O regime militar no livro didático de ensino médio: a construção de uma memória. 2008. Disponível em: http://tede.pucrs.br/tde_busca/arquivo.php?codArquivo=1572>. Acesso em: 13 de junho de 2014.

SALLES, A. M. O Livro didático como objeto e fonte de pesquisa histórica e educacional. Revista Semina, v. 10, p.1-16, 2011.

SILVA, P. R. A (In)visibilidade indígena no livro didático de História do ensino médio. In: Anais do XVI Encontro Regional de História da Anpuh-Rio: Saberes e Práticas Científicas. Rio de Janeiro: Anpuh, 2014. p. 1-15.

TV FOLHA. Vídeo Sugere que Ditadura Ensinou Indígenas a Torturar. 2012. Disponível em: https://www.youtube.com/watch?v=H0s4m1WQNmg>. Acesso em: 31 de março de 2014.

VALENTE, L. F. Paulo Freire: desenvolvimento como prática da liberdade. ALCEU, v. 9, n. 18, p. 186-197, jan./jun. 2009.

WORSTER. D. Para fazer história ambiental. Estudos Históricos, Rio de Janeiro, v. 4, n. 8, p. 198$215,1991$.

Recebido em: 26/11/2015

Aceito em: 05/07/2016 